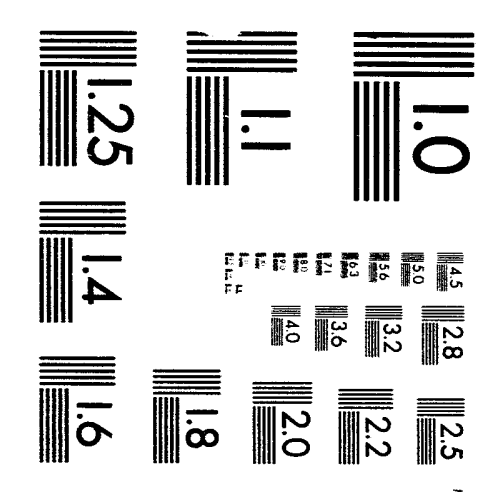



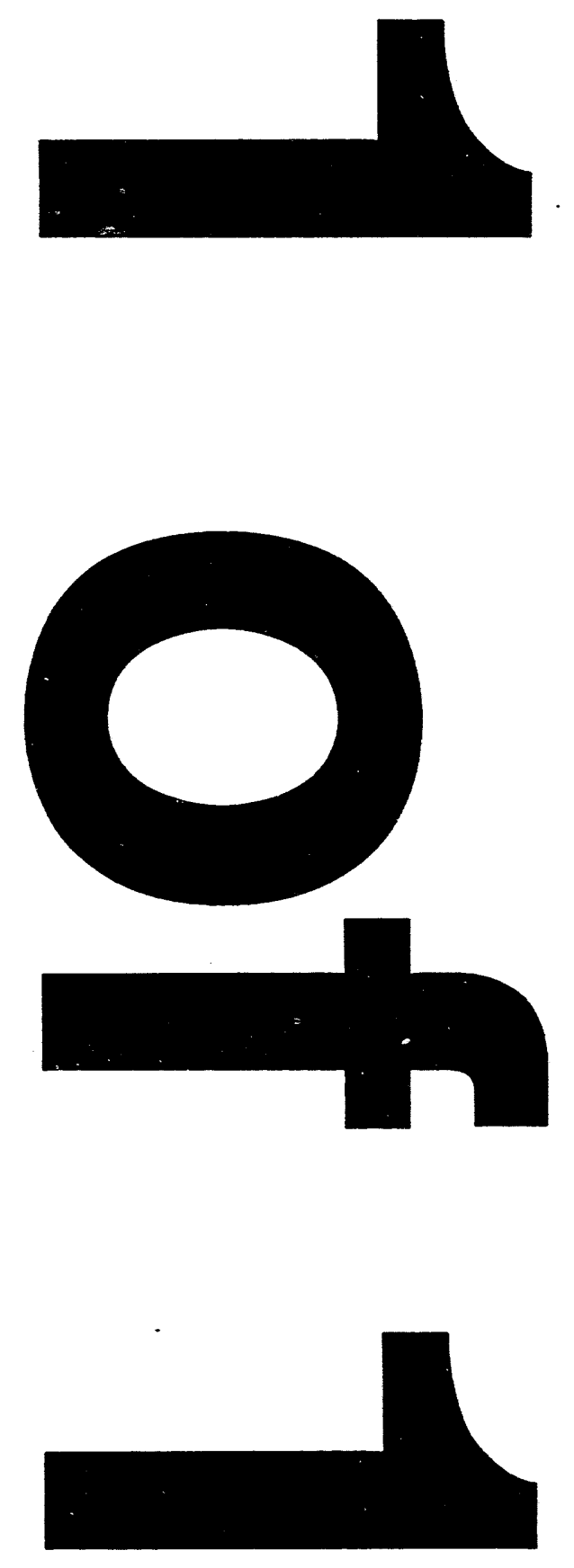


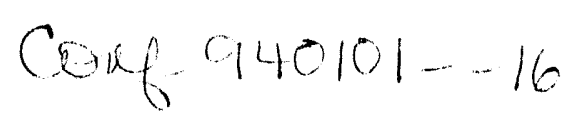

LA-UR-9 $3-3651$

Title: MODELLING THE MASS MIGRATION PHENOMENA IN PARTIALLY FROZEN HEAT PIPES

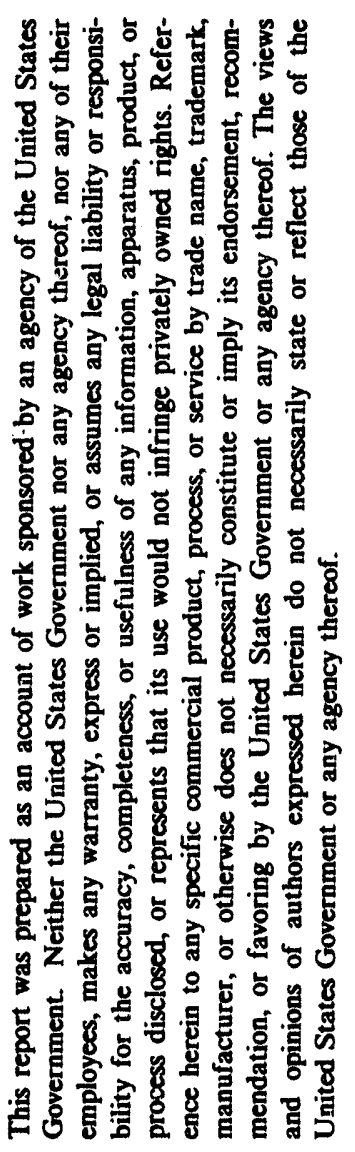

Author(s): $\begin{aligned} & \text { Michael D. Keddy, MEE-13, LANL } \\ & \text { Michaei A. Merrigan, MEE-13, LANL } \\ & \text { Eric Critchley, PL }\end{aligned}$

Submitted to:

11 th Symposium on Space Nuclear Power and Propulsion Albuquerque, NM January $9-13,1994$

\section{Los Alamos} NATIONAL LABORATORY

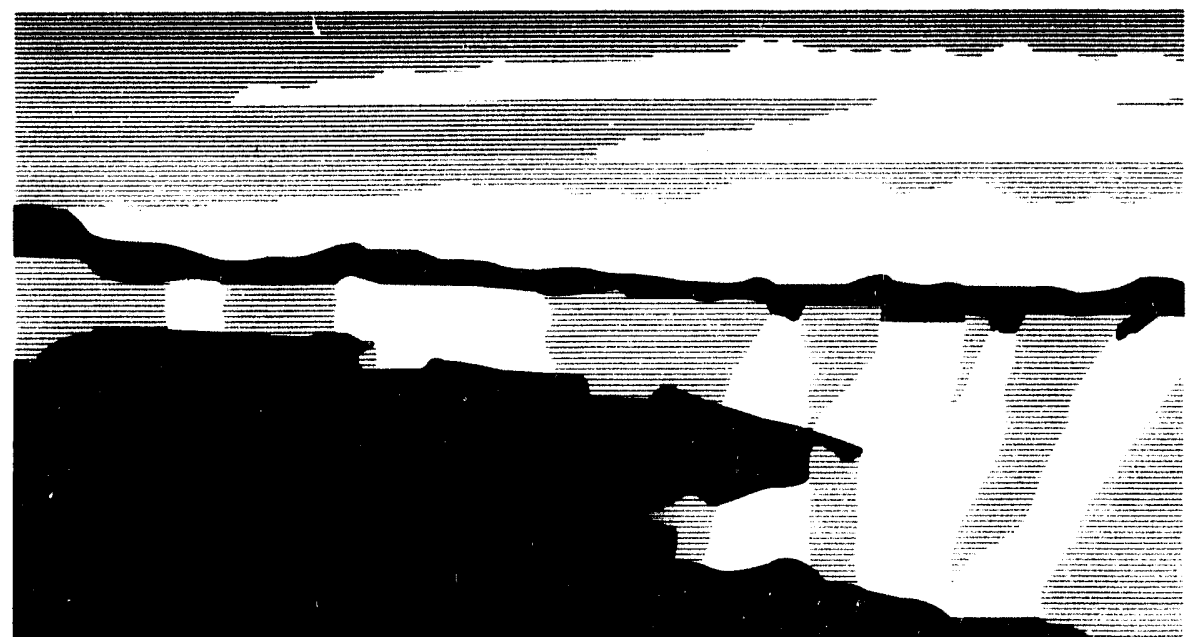

Los Alamos National Laboratory, an affirmative action/equal opportunity emplóyer, is operated by the University of Callfornia for the U.S. Department of Energy under contract W-7405-ENG-36. By acceptence of this article, the publisher recognizes that the U.S. Government retains a nonexclusive, royalty-free license to publish or reproduce the published form of this contribution, or to allow others to do so, for U.S. Government purposes. The Los Alamos National Laboratory requests that the publisher identity this article as work pertormed under the auspices of the U.S. Department of Energy. 


\title{
Modelling the Mass Migration Phenomena in Partially Frozen Heat Pipes
}

\author{
Michael D. Keddy \\ Los Alamos National Laboratory \\ Los Alamos, NM \\ (505) $667-3664$
}

\author{
Michael A. Merrigan \\ Los Alamos National Laboratory \\ Los Alamos, NM \\ (505) $667-6466$
}

\author{
Eric Critchley \\ Phillips Laboratory \\ Albuquerque, NM \\ (505) $846-2438$
}

\begin{abstract}
Liquid metal heat pipes operated at povier throughputs well below their design point and with sink temperatures below the freezing temperature of the working fluid may fail as a result of the working fluid migrating to a cold region within the pipe, freezing there, and not returning to the evaporator section. Eventually, sufficient working fluid inventory may be lost to the cold region to cause a local dry-out condition in the evaporator. A joint experimental and analytical effort by the Air Force Phillips Laboratory and Los Alamos National Laboratory is underway to investigate this phenomena. This paper presents an analytical model developed to describe this phenomena. The model provides for analytic determination of heat pipe temperature profiles, freeze-front locations and mass migration rates.
\end{abstract}

Laboratory tests have demonstrated that in operating high temperature, radiative coupled heat pipes below their heat throughput design point, a part of the condenser will operate near the evaporator exit temperature, essentially isothermal. At the end of this region, the temperature falls sharply and can reach values below the fusion temperature for the working fluid, provided the heat sink temperature is low enough. This temperature decline occurs over a length corresponding to a few heat pipe diameters.

To illustrate this, Figure 1 shows a temperature profile for a potassium heat pipe operated well below its design point. This heat pipe was constructed of niobium$1.0 \%$ zirconium with an annular screen wick. The heat pipe was $1.52 \mathrm{~cm}$ in diameter and approximately 1.0 meter long. The heated length was $11 \mathrm{~cm}$. Heat removal was by radiation over the entire length. The heat pipe was operated at steady state, with an approximate power throughput at the evaporator exit of $65 \mathrm{~W}$. It was designed to transport $650 \mathrm{~W}$ at $800 \mathrm{~K}$ (Woloshun, et al. 1990).

A heat pipe operating well below its design point in a low temperature heat sink will slowly deplete its usable supply of working fluid as a result of fluid freezing in the condenser and not being cycled back to the evaporator. For long-term, low-power operation of heat pipe radiator elements in space power systems, this mode of operation may lead to system failure.

In order to determine the rate at which the working fluid migrates from the molten region to the frozen region, it is necessary to establish the point at which freezing begins. To do so by analytic means requires the use of a model for the flowing vapor in the condenser. The heat pipe wall temperature is strongly dependent upon the vapor stream temperature, and freezing will start to occur at the point along the wall where the temperature is equal to the working fluid fusion temperature. The vapor as it leaves the evaporator is in continuum flow. The vapor which comes into contact with the heat pipe wall will condense, transferring its absorbed heat to the surroundings, meanwhile leaving the vapor progressively more and more rarefied. Eventually, a sufficient amount of vapor will have condensed out of the stream such that the assumption of zero velocity for the vapor at the wall is no longer valid (Brown, et al. 1946). This type of flow is termed slip flow, or transition flow. Eventually, the flowing vapor becomes so 


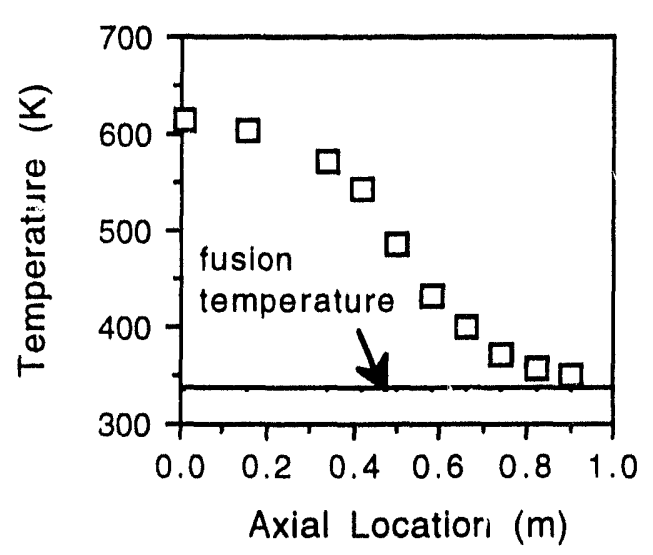

FIGURE 1. Low Power Temperature Profile Data for a Potassium Heat Pipe

rarefied as to be in free molecular flow. This flow occurs when the mean free path for the molecules is approximately equal to the characteristic dimension for the channel (Perry and Green 1984), (in this case the heat pipe inside diameter.) It is in the regions of slip flow and free molecular flow that the sharp temperature decline along the outside heat pipe surface is observed.

\section{EXPERIMENTAL RESULTS}

A joint experimental and analytic investigation of the performance of heat pipes operated well below their design points is being undertaken jointly by the Air Force Phillips Laboratory and Los Alamos National Laboratory. The objectives of this effort are to experimentally observe and measure the rate of mass migration into the frozen region within heat pipes and develop a combined analytical and empirical model capable of predicting those rates for liquid metal heat pipes operating well below their design points. As a result, the operating parameters for heat pipes intended for this type of operation, such as is the case for some spacecraft radiators, will be defined. This will ultimately lead to the formulation of heat pipe designs not subject to failure as a result of internal migration and freezing of working fluid.

The experiments include both high temperature, liquid metal heat pipes and low temperature heat pipes. The modeling effort concentrated on the development of a first order analytical model which could be coded and executed on a desktop computer. This paper focuses on the development of this model.

\section{ANALYTICAL DEVELOPMENT}

Considei the control surface of length $\mathbf{d x}$ shown in Figure 2. Mass flows into the surface at a rate $w$ on the left side, and flows out at a rate $w+d w$ on the right. Heat flows out of the volume at a raie $\mathbf{d Q}$ as a result of the condensation of vapor which occurs at a mass flow rate of $d w$.

The mass flow rate is directly related to the heat throughput. Assuming sensible heat is negligible, compared to the latent heat of vaporization, then the mass throughput at any given location along the heat pipe condenser can be written as

$$
\mathrm{w}=\frac{\mathrm{Q}}{\mathrm{h}_{\mathrm{fg}}}
$$

The rate of change of mass throughput, or condensation rate is then defined by the relation

$$
\delta w=\frac{\delta Q}{h_{f g}}
$$

And the heat transfer rate is described by

$$
\delta Q=\bar{H}(\pi \mathrm{D} \delta \mathrm{x})\left[\mathrm{T}-\mathrm{T}_{\text {sink }}\right]
$$

For a discrete element of length $\delta x$, we designate the upstream location as point 1 and the downstream location as point 2. A one-dimensional compressible flow with constant specific heat and molecular weight is assumed. We further assume that the vapor is an ideal gas; that the stagnation 


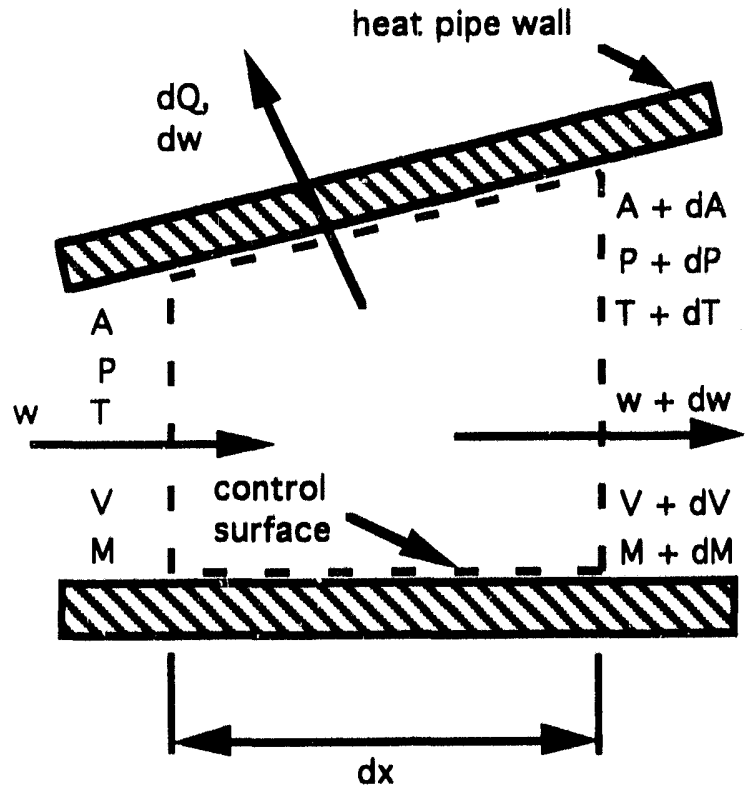

FIGURE 2. Control Surface for Vapor Flow in a Heat Pipe Condenser

temperature is constant; and that the cross sectional area is constant. Then, following the derivations of Shapiro (1953) the change in pressure across the control surface can be described by:

$\frac{P_{2}}{P_{1}}=\frac{w_{2}}{w_{1}} \frac{M_{1}}{M_{2}}\left[\frac{1+\frac{\gamma-1}{2} M_{1}^{2}}{1+\frac{\gamma-1}{2} M_{2}^{2}}\right]^{1 / 2}$

And an expression for the change in Mach number as a function of location along the condenser and mass removal rate can be written in differential form as

$$
\begin{aligned}
\frac{d M^{2}}{M^{2}} & =\frac{\gamma M^{2}\left(1+\frac{\gamma-1}{2} M^{2}\right)}{1-M^{2}}\left(4 f \frac{d x}{D}-2 y \frac{d w}{w}\right. \\
& +\frac{2\left(1+\gamma M^{2}\right)\left(1+\frac{\gamma-1}{2} M^{2}\right)}{1-M^{2}} \frac{d w}{w}
\end{aligned}
$$

With the coefficient of friction defined in the following manner

$$
\tau_{w} \equiv \frac{f \rho V^{2}}{2}
$$

Where $\tau_{w}$ is the wall shearing stress. The factor $y$ is defined as the ratio of the component of velocity for the injected flow (for example, condensation or evaporation) in the direction of the main flow to the velocity for the main flow.

Making certain assumptions about heat rejection and friction, it is possible to integrate equation (5) in closed form. Assume that for a sufficiently small interval, $\mathrm{dx}$, between points 1 and 2 , the heat rejection rate (mass removal rate) is constant. Thus, the mass throughput is a linear function of location, resulting in

$w=w_{1}-B x$ and $d w=-B d x$

Where the subscript 1 refers to the upstream location. Further assume that $y=1$. Substitution into equation (5) gives:

$\frac{d M^{2}}{M^{2}}=\left[\frac{1+\frac{\gamma-1}{2} M^{2}}{1-M^{2}}\right]\left(\gamma M^{2} * 4 f \frac{d x}{D}-2 \frac{B d x}{w_{1}-B x}\right)$

Assuming the friction factor to be a linear function of Reynolds number

$$
f=\frac{f}{\operatorname{Re}_{D}}=f^{\prime} \frac{\mu \pi D}{4 w}
$$

yields the following differential equation

$$
\begin{aligned}
\frac{d M^{2}}{M^{2}}= & {\left[\frac{1+\frac{\gamma-1}{2} M^{2}}{1-M^{2}}\right] } \\
& *\left(\gamma M^{2} * f^{\prime} \frac{\mu \pi}{w}-2 \frac{B}{w_{1}-B x}\right) d x
\end{aligned}
$$


Which may be rearranged as

$$
\begin{aligned}
\frac{\mathrm{dM}^{2}}{\mathrm{M}^{2}}= & {\left[\frac{1+\frac{\gamma-1}{2} M^{2}}{1-M^{2}}\right] } \\
& *\left(2-\gamma M^{2} * f \frac{\mu \pi}{B}\right)\left(\frac{-B d x}{w_{1}-B x}\right)
\end{aligned}
$$

or

$\frac{d M^{2}}{M^{2}}=\left[\frac{1+a M^{2}}{1-M^{2}}\right]\left(2-b M^{2}\right) \frac{d w}{w}$

where

$a=\frac{\gamma-1}{2} \quad$ and $\quad b=\gamma^{*} f^{\prime} \frac{\mu \pi}{B}$

This expression can then be integrated by the technique of separation of variables.

The result is

$\frac{w_{1}}{w_{2}}=\frac{M_{2}}{M_{1}}\left(\frac{1+a M_{1}^{2}}{1+a M_{2}^{2}}\right)^{\frac{a+1}{2 a+b}}\left(\frac{2-b M_{2}^{2}}{2-b M_{1}^{2}}\right)^{\frac{1-b}{2 a+b}}$

Equations (1) through (13) comprise the analytical model. Implementation of the model proceeds as follows. First, the heat pipe condenser is divided into discrete sections, each of length $\delta x$. It is assumed that the distance $\delta x$ is sufficiently small such that the properties for the entire section can be described by the upstream conditions.

Solution of the various properties at each section then proceeds in a forward marching fashion. With knowledge of the upstream conditions at the first section, the properties at the section exit (i.e., inlet to the next section) are determined. The solution then proceeds for each subsequent section. First, the heat sink is defined in terms of sink temperature and equivalent heat transfer coefficient $\left(T_{\text {sink }}\right.$ and $\left.\bar{H}\right)$. The heat transfer coefficient may be a function of temperature as is the case for radiation; however, as with the other properties, it is considered constant over each discrete element. Equation ( 3 ) is then solved for the incremental heat transfer rate, $\delta Q$. Equation (2) is solved for the condensation rate, $\delta \mathrm{w}$, and the downstream mass flowrate is thus determined. Equation (13) is used to determine the downstream Mach number, and then equation (4) is solved for the downstream pressure.

The working fluid in a heat pipe exists as a two-phase fluid. Thus, the vapor and liquid in the condenser region coexist under saturation conditions. This implies that the temperature and pressure are directly related (for example, $T=T(P)$ only). With knowledge of an appropriate equation of state, the downstream temperature can be determined from the downstream pressure. This temperature then determines the heat rejection rate at the next downstream section, and the solution proceeds as before until the temperature reaches the fusion temperature for the working fluid. The physical location where this occurs is the freeze-front for the working fluid. At this point the calculations are terminated. The mass throughput at this point is the predicted mass migration rate for the heat pipe design in question.

In order to start the model, it is necessary to characterize the flow conditions at the inlet to the condenser. Several studies have been done in the past to examine the startup behavior of heat pipe (Cotter 1967, Deverall et al., 1970, and Busse 1973).. The conditions that exist during start-up are analogous to those that exist for a heat pipe being operated at power levels substantially below its design point. At the evaporator exit, which is the condenser Inlet in heat pipes without adiabatic sections, the vapor flow is said to be choked. That is, rio additional mass can be added to the vapor stream without changing the operating constraints on the heat pipe (such as evaporator temperature, heat sink temperature or respective heat transfer coefficients). Under these conditions (for example, Mach number = 1), the heat pipe is said to be operating at its sonic limit. The 
heat transfer throughput at the evaporator exit is given by

$\mathrm{Q}_{\text {sonic }}=\frac{\rho_{0} \mathrm{~A} \sqrt{\gamma \mathrm{RT}_{0}}}{\sqrt{2(\gamma+1)})} h_{\mathrm{fg}}$

And the temperature is

$\mathrm{T}_{\text {sonic }}=\frac{2}{\gamma+1} \mathrm{~T}_{\mathrm{o}}$

The saturation pressure can then be found from the saturation curve, so the evaporator exit conditions (i.e., condenser inlet conditions) are fully characterized. The information necessary to implement the mass migration model is thus complete.

\section{SUMMARY}

The one-dimensional heat pipe working fluid migration model described herein is being programmed on a desk top computer. Once the code is complete it will be used to predict the temperature profiles and mass migration rates for liquid metal heat pipes operated substantially below their design points. The model results will be compared with experimental data. A sodium heat pipe experiment will be conducted at the Air Force Phillips Laboratory to generate this data as part of this overall program.

\section{Acknowledgments}

This work is a joint experimental and analytical effort by the Alr Force Phillips Laboratory and Los Alamos National Laboratory.

\section{References}

Brown, G. P., A. DiNardo, G. K. Cheng, and T. K. Sherwood (1946) "The Flow of Gases in Pipes at Low Pressure, Journal of Applied Physics, 17: pp. 802-813.

Busse, C.A. (1973) "Theory of the Uitimate Heat Transfer Limit of Cylindrical Heat Pipes, "Int. J, Heat Mass Transfer, vol. 16, pp 169-186, Pergamon Press.
Cotter, T.P. (1967) "Heat Pipe Startup Dynamics," Thermionic Conversion Specialist Conference, Palo Alto, CA.

Deverall, J.E., J.E. Kemme, and L.W. Florschuetz (1970) "Sonic Limitations and Startup Problems of Heat Pipes," Los Alamos Scientific Laboratory, LA-4518.

Perry, R. H. and D. Green (1984) Perry's Chemical Engineers' Handbook., Sixth ed., Sec. 5, McGraw-Hill Publishing Co., NY.

sc

Shapiro, A. H. (1953) The Dynamics and Thermodynamics of Compressible Fluid Flow, Ronald Press Co. vol. I.

Woloshun, K. A., J. T.Sena, E. S. Keddy, ; and M. A.Merrigan (1990) "Radial Heat Flux Limits in Potassium Heat Pipes: An Experimental and Analytical Investigation," Proceedings of the 7th Symposium on Space Nuclear Power Systems, The Institute for Space Nuclear Power Studies, Chemicall Nuclear Engineering Department, University of New Mexico, Albuquerque NM 87131. 

